\title{
Reporting null results and advancing science
}

Sandra J. Petty, MBBS, FRACP, PhD, and Robert A. Gross, MD, PhD

Neurolog ${ }^{\circledR}$ 2019;92:827-828. doi:10.1212/WNL.0000000000007400
Correspondence

Dr. Petty

Sandy@cbmrt.org

Publication bias is a well-known issue among scientists and clinicians. Research waste is very much in focus among funders and the scientific community, and one of the factors contributing to this wastage is the nonpublication of negative data; that is, data that do not support the initial hypothesis. Through Neurology Null Hypothesis, the American Academy of Neurology (AAN), Neurology, and AAN members are enhancing research culture and opportunities for researchers to reach scientists and clinicians with their findings. Together we can all promote a more balanced and complete publication culture.

We are delighted to welcome you to the first Neurology Null Hypothesis Special Edition. This print collection constitutes articles that published online ahead of print, so as to bring the result forward in a timely manner. When we devised this Special Edition, we aimed to reach the desks, screens, and kitchen tables of every Neurology reader to maximize the availability of these articles. We encourage you to read, cite and contribute your research to this important ongoing initiative. By so doing, together we acknowledge that good science encompasses more than positive data outcomes; that null data address publication bias and better inform research design.

How have we done so far?

Messacar et al. examined the safety, tolerability, and efficacy of fluoxetine as an antiviral for acute flaccid myelitis. This study demonstrated tolerability but not efficacy in a retrospective study in response to an outbreak of EV-D68 acute flaccid myelitis, as an off-label treatment in the context of efficacy failure of known treatments, including several antivirals. Patients receiving more than one dose of fluoxetine (a median of 5 days after the neurologic onset) had a more severe neurologic nadir, and were more likely to have tested positive to EV-D68, with poorer long-term outcomes, than patients not treated with fluoxetine. The authors highlight the need for rapid detection of EV-D68 alongside the suggestion to study treatment initiated prior to the neurologic nadir, the need for prospective well-designed research, as well as national and international collaborative networks to power trials adequately at times of outbreaks. Furthermore, timely and accessible reporting of study results, including negative findings during outbreaks, can inform clinicians to guide patient treatment, and avoid treatments that do not work.

Statins were in focus in 2 studies that were informative for clinicians as well as future research design: one by Warendorf et al. finding no association between axonal polyneuropathy and statin usage, which highlighted the importance of good study design; and another by Witsch et al. that confirmed their null hypothesis, that prior home use of statins would have no effect on perihaemorrhagic edema to hematoma ratio ( $\mathrm{rPHE}$ ), but that duration to CT needs to be accounted for in future studies.

Collaborations studying relatively rare diseases were highlighted, with findings that will further inform clinicians and research design:

- Dr Kjetil Bjornevik et al. aimed to assess whether prediagnostic levels of plasma branchedchain amino acids (BCAAs) — valine, leucine, and isoleucine-were associated with

From the Center for Biomedical Research Transparency (S.P.), New York, NY; Department of Medical Education (S.P.), Melbourne Medical School, The University of Melbourne; St. Vincent's Hospital (S.P.); Department of Neuroscience (S.P.), CCS, Monash University; Department of Neurology (S.P.), Alfred Health, Melbourne, Australia; and University of Rochester Medical Center (R.A.G.), NY.

Go to Neurology.org/N for full disclosures. Funding information and disclosures deemed relevant by the authors, if any, are provided at the end of the article. 
amyotrophic lateral sclerosis (ALS) risk. From a pooled analysis of 5 large cohort studies, 275 patients with ALS later developed ALS, but there was no association between prediagnostic plasma levels of BCAAs and the risk of ALS. In a low-incidence disease, the pooling of cohorts can be useful, but also poses some limitations, including harmonization of data collection and laboratory testing.

- Cubo et al. aimed to identify phenotypic differences in homozygous vs heterozygous patients with Huntington disease. Using an international, longitudinal case-control study, they found that homozygosity for CAG repeat expansion was infrequent: 28 homozygous and 10,893 heterozygous patients were included in the study. After adjustment for multiple comparisons, homozygosity did not alter the age at onset, clinical phenotype, or disease progression; however, interpretation was limited by the low number and short duration of follow-up of homozygous patients.

Efficacy and safety findings were of interest:

- Lochmüller et al. demonstrated lack of efficacy of an extended-release formulation of aceneuramic acid as a treatment for patients with the hereditary inclusion body myopathy GNE myopathy. The authors found no difference in a combined upper extremity muscle strength score or secondary endpoints after 48 weeks of therapy vs placebo, despite a demonstrated increase in serum sialic acid. A case of acute gastritis was the only reported severe adverse event flagged as possibly treatment-related. There were differences in clinical characteristics of cohorts between the phase 2 and 3 studies; a longer treatment period was suggested, alongside some biologic theories for the lack of demonstrated efficacy that should be taken into consideration ahead of future research.

- Meyer and Tremblay-Mercier et al. performed a 2-year double-masked randomized study of low-dose naproxen ( $220 \mathrm{mg}$ bd) in cognitively healthy patients with positive family history of Alzheimer disease (AD). While naproxen did not reduce apparent progression of presymptomatic $\mathrm{AD}$ in this study, there were adverse effects. Post hoc, the authors highlighted factors that contributed to a reduction in projected study power, as well as newer biomarkers that might improve power in future studies.

- Cortese et al. investigated whether minerals play a role in multiple sclerosis (MS) pathogenesis. Intakes of potassium, magnesium, calcium, phosphorous, iron, zinc, manganese, and copper were analyzed from data in the Nurses Health Study and Nurses Health Study II. There was no association between mineral intake and MS risk.

- Galhardoni et al. examined pain intensity following deeprepetitive transcranial magnetic stimulation, compared to placebo, at the posterior superior insula or anterior cingulate cortex in patients with central neuropathic pain. There was no difference in clinically measured pain intensity; however, heat pain threshold was increased in patients receiving posterior superior insula stimulation, and anxiety scores were reduced in patients who underwent anterior cingulate cortex stimulationfindings that are of interest.

We thank all the authors who submitted papers, and the research participants for their contribution. Congratulations to the authors and institutions whose work has been accepted for publication in this inaugural edition. We thank the AAN for its support and to staff and editorial board and reviewers of Neurology and Wolters Kluwer for their support in this new initiative to reduce publication bias.

\section{Study funding}

No targeted funding reported.

\section{Disclosure}

Sandra Petty reports no disclosures. Robert A. Gross has received honorarium from AAN as Editor-in-Chief of Neurology; serves as the Editor-in-Chief of Neurology; has received publishing royalties for the Neurology in Practice series and from Blackwell-Wiley; has conducted clinical trials funded by GlaxoSmithKline, UCB, Ortho-McNeil, Pfizer, and Marinus, but has ceased participation in industry-sponsored clinical trials and speakers' bureau since his appointment as EIC for Neurology (2009); has received governmental research support from the NIH/National Center for Advancing Translational Sciences; and has received academic support for educational endeavors from the University of Rochester Medical Center. Go to Neurology.org/N for full disclosures. 


\section{Neurology}

\section{Reporting null results and advancing science Sandra J. Petty and Robert A. Gross \\ Neurology 2019;92;827-828 Published Online before print March 29, 2019 \\ DOI 10.1212/WNL.0000000000007400}

This information is current as of March 29, 2019

$\begin{array}{ll}\begin{array}{l}\text { Updated Information \& } \\ \text { Services }\end{array} & \begin{array}{l}\text { including high resolution figures, can be found at: } \\ \text { http://n.neurology.org/content/92/18/827.full }\end{array} \\ \text { Subspecialty Collections } & \begin{array}{l}\text { This article, along with others on similar topics, appears in the } \\ \text { following collection(s): } \\ \text { All CBMRT/Null Hypothesis } \\ \text { http://n.neurology.org/cgi/collection/all_cbmrt_null_hypothesis }\end{array} \\ & \begin{array}{l}\text { Information about reproducing this article in parts (figures,tables) or in } \\ \text { its entirety can be found online at: } \\ \text { http://www.neurology.org/about/about_the_journal\#permissions }\end{array} \\ \text { Permissions \& Licensing } & \text { Information about ordering reprints can be found online: } \\ \text { http://n.neurology.org/subscribers/advertise }\end{array}$

Neurology ${ }^{\circledR}$ is the official journal of the American Academy of Neurology. Published continuously since 1951, it is now a weekly with 48 issues per year. Copyright (O 2019 American Academy of Neurology. All rights reserved. Print ISSN: 0028-3878. Online ISSN: 1526-632X.

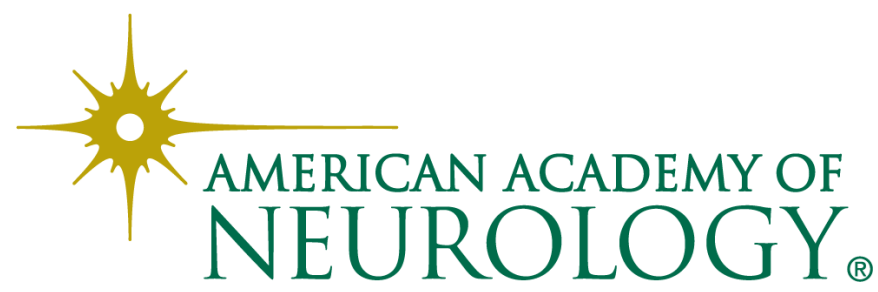

